\title{
Internacionalización de Compañías Petroleras y Límites a la Planificación Nacional del Desarrollo
}

\section{Internationalization of Oil Companies and Limits to National Development Planning}

Fernando German Dachevsky*

\begin{abstract}
Resumen: El presente trabajo se propone contribuir al estudio de los condicionamientos actuales a la planificación del desarrollo nacional en países petroleros, a partir de un análisis de los cambios ocurridos, durante las últimas décadas, en la organización de la industria petrolera. Nos referimos particularmente al proceso de internacionalización de compañías nacionales y sus efectos en la capacidad de los gobiernos propietarios de establecer mecanismos de apropiación y distribución de renta petrolera. Con este objetivo, el artículo comienza analizando ciertas particularidades en el desarrollo de la propiedad territorial en la industria petrolera. Allí buscamos mostrar determinantes históricos para entender la relación entre compañías nacionales y desarrollo interno de los países exportadores. Luego se presenta un análisis de los compromisos que actualmente regulan a la producción energética a nivel mundial y aquellos que, durante las últimas décadas, fueron firmados por los países petroleros. Allí advertiremos crecientes limitaciones a la apropiación y distribución nacional de la renta.
\end{abstract}

Palabras-clave: Internacionalización. Renta de la tierra petrolera. Propiedad nacional.

Abstract: The objective of this paper is to discuss current constraints in planning of national development in oil-producing countries, resulting from changes that occurred during the last decades in the organization oil industry. We will focus particularly on the process of internationalization of national companies and their impact on the ability of governments to apply mechanisms of appropriation and distribution of oil revenues. With this objective, the article starts analyzing certain peculiarities in the development of land ownership in the oil industry. Here we attempt to point out historical determinants that are necessary to take into account to understand the relationship between emergence of national companies and internal development of the exporting countries. Then we will present an analysis of the treaties that currently rule international production of energy and of the investment treaties that were sign by the oil producing countries in recent decades. There we will note increasing limitations on national appropriation and distribution of land rent.

Keywords: Internationalization. Oil land rent. National ownership.

JEL Classification: F21; F22; F50.

Doctor en Historia por la Universidad de Buenos Aires (UBA). Magister en Relaciones Económicas Internacionales por la UBA. Investigador en Instituto de Investigaciones Económicas, Facultad de Ciencias Económicas, CONICET-UBA. E-mail: fdachevsky@gmail.com 


\section{Introducción}

En el presente trabajo nos proponemos contribuir al estudio de los condicionamientos actuales a la planificación de políticas de desarrollo nacional en países petroleros. Para ello pondremos énfasis en el proceso de internacionalización de compañías internacionales y sus efectos en la capacidad de los gobiernos propietarios de establecer mecanismos de apropiación y distribución de renta petrolera.

En función de nuestro propósito, la primera parte del presente trabajo estará dedicada a identificar ciertas determinaciones específicas de la renta de la tierra en la industria petrolera y su desarrollo histórico. En particular, nos referiremos los problemas que impone propiedad privada de la tierra petrolera a un desarrollo intensivo de la acumulación de capital en el petróleo. Allí señalaremos que la división de la propiedad de la tierra entre propiedad del suelo y propiedad del subsuelo alienta la estatización de la misma. Es decir, que la estatización de la tierra, lejos de ser una traba para el capital petrolero privado permite fijar condiciones óptimas para su desenvolvimiento. Luego, observaremos el modo en que en los países exportadores de petróleo la propiedad estatal de los yacimientos se desarrolló históricamente, diferenciando dos grandes etapas. La primera, que transcurre desde la década de 1950 hasta las nacionalizaciones de la década de 1970, donde se observa un proceso por el cual la propiedad estatal librada al capital privado se transforma en una propiedad que, siguiendo la conceptualización propuesta por Mommer $(1988,2003)$, llamaremos de tipo nacional. Es decir, en una forma de propiedad que tendrá como objetivo la aplicación de una mayor carga rentística necesaria para el sostenimiento de la economía no petrolera. La segunda etapa remite al proceso de internacionalización de activos de las compañías nacionales ocurrido desde la década de 1980 y que llevará a los países exportadores a firmar nuevos compromisos internacionales atenientes a la industria petrolera, resignificando el rol de las compañías nacionales y socavando las bases de la propiedad nacional. Dando cuenta del marco histórico descripto en la primera parte, la segunda parte del trabajo está destinada a observar de dichos compromisos internacionales. En particular, nos detendremos analizar el acercamiento de los países de la OPEP a un marco jurídico emergente, sobre todo desde la década de 1990, que, diseñado en función de los intereses de los grandes países consumidores de petróleo, comenzó a ganar peso a nivel internacional. Nuestro objetivo será mostrar que la aparición de dichos acuerdos multilaterales y bilaterales de inversión de conjunto presenta un escenario de transformación de las relaciones entre compañías nacionales y

Estados propietarios, implicando crecientes dificultades para el sostenimiento de la propiedad nacional. 


\section{Sobre la Propiedad Nacional de la Tierra Petrolera}

Si bien el rol de la propiedad territorial en la economía capitalista ha perdido peso en la bibliografía, consideramos que sigue siendo fundamental para entender el desarrollo de países basados en la exportación de recursos naturales. En este sentido, la renta de la tierra siegue siendo un problema central para el abordaje de las economías latinoamericanas.

La renta de la tierra contiene una gran cantidad de problemáticas teóricas respecto de su formación, sus tendencias, sus ciclos, el lugar de diferencias naturales y tecnológicas, entre otras. A fines del presente trabajo nos interesa detenernos en la relación específica entre el propietario del suelo y el arrendatario.

A partir de los estudios de Marx (1981) descubrimos la existencia una relación inherentemente antagónica entre terratenientes y capitalistas, donde la condición de terratenientes no deriva del carácter diferencial del valor de uso de la tierra, sino de la propiedad en sí de un valor de uso social no reproducible por el trabajo humano. Es decir, al reconocer la renta como un componente específico y necesario del precio de las mercancías basadas en la explotación de recursos no reproducibles por el trabajo humano, Marx encuentra que la explotación de tierras contiene la necesidad de un sujeto social, cualitativamente distinto de la clase capitalista y la clase obrera, que personifique la propiedad del suelo. Es decir, un sujeto terrateniente.

El antagonismo entre el propietario de la tierra y el propietario del capital aparece como un tipo de relación inevitable de la acumulación de capital. Marx reconoce que este tipo de relación, dado el proceso histórico por el cual se desarrolló la acumulación originaria, habría tomado la forma inicial de propietarios privados de la tierra. Sin embargo, la forma de propiedad privada de la tierra se constituye, según Marx, en una creciente traba para la acumulación:

[...] la existencia de la propiedad misma de la tierra se considera como una manifestación puramente transitoria, necesaria en cuanto acción del capital sobre las viejas relaciones de propiedad de la tierra, y como un producto de la disolución de esas relaciones; pero en cuanto tal, una vez alcanzado ese objetivo, la propiedad de la tierra no constituye otra cosa que una traba para el beneficio, en absoluto es necesario para la producción. El capital, pues, procura disolver la propiedad de la tierra en cuanto propiedad privada y transferirla al Estado (MARX, 2009, p. 221).

Las formas concretas con que se efectiviza esta necesidad del modo de producción capitalista por superar las trabas que impone la propiedad privada de la tierra, solo pueden ser reconocidas a partir de la investigación sobre la relación tierra-capital en las diferentes esferas de la producción. La industria petrolera constituye un observable fundamental en este sentido dado que en ella la 
contradicción entre capital y terratenientes se ha desplegado en formas bastantes diversificadas.

El caso norteamericano (donde todavía persiste la propiedad privada de los yacimientos) es una muestra de cómo a la acumulación de capital petrolero, que se caracterizó siempre por concentrar grandes masas de capital fijo, se le interponen las limitaciones de la propiedad privada del territorio. Cabe señalar que la industria petrolera posee la particularidad de que la propiedad de la tierra está escindida entre propiedad del suelo y propiedad del subsuelo. A diferencia de la generalidad de los países petroleros donde dicha separación fue la base de una temprana estatización del subsuelo, ${ }^{1}$ en los Estados Unidos, la propiedad del mismo aparece desde el origen como un atributo de la propiedad del suelo. Lo cual, brindaba la posibilidad de que el propietario superficial accediera a la propiedad del subsuelo. ${ }^{2}$ Pero a diferencia de la minería donde el subsuelo era asignado a los propietarios superficiales, en el petróleo la propiedad estaba garantizada a partir de la captura. Es decir, que el petróleo era de quien lo extrajera primero. Esta forma de propiedad de los yacimientos de petróleo supuso fuertes trabas que persisten hasta la actualidad, para una explotación eficiente. Dado que solo de manera excepcional la propiedad superficial coincidirá en tamaño, ubicación y forma con el yacimiento, la fragmentación en múltiples propietarios superficiales determina un grado mayor de anarquía la extracción. Anarquía que condujo, no solo a una sobreproducción de petróleo acompañada de una violenta caída de precios a finales de siglo XIX, sino también a un pronto agotamiento de los yacimientos. Cabe señalar que estudios como el de Miller (1973) nos muestra que para 1970 la fragmentación superficial de la tierra prevalecía como una traba para la inversión de capital, determinando que la mayor parte de la producción de este país proviniese de pequeños arrendamientos. Según el autor, dicha estructura de la propiedad tiene como consecuencia que la rentabilidad de un capital decaiga a medida que arrienda más tierras, por tener que lidiar con mayor cantidad de terratenientes. Autores como Bina (2011) reconocen en el citado estudio de Miller las razones de la caída de rendimientos de la producción petrolera norteamericana registrada en la década de 1970. Teniendo en cuenta que la producción norteamericana se consolidaría como reguladora de los precios internacionales del crudo sería, a su vez, según Bina, determinante en la suba de precios de 1973-1974.

$1 \quad$ Tal es el caso de la Argentina, donde desde 1886 se estableció que sea quien fuere el propietario del suelo, la propiedad del subsuelo quedaría reservada al Estado.

2 No nos detendremos aquí en analizar las particularidades que determinaron la temprana consolidación de la propiedad privada del subsuelo en los Estados Unidos. Aunque cabe señalar que, a diferencia de otros países, donde el petróleo fue descubierto bajo tierras fiscales y sin gran valor agrícola, en el país del norte la propiedad superficial se encontraba más densamente poblada y fragmentada en explotaciones agrarias (DACHEVSKY, 2013). 
Ahora bien, así como la política petrolera norteamericana nos da un ejemplo de un largo e infructuoso camino recorrido para gradualmente subordinar a los terratenientes privados, la generalidad de los países petroleros presentan, dadas particularidades de sus formaciones económicas nacionales, que no analizaremos aquí, una temprana estatización de la propiedad de los mismos. Es decir, lo que Mommer $(1988,2003)$ denomina como la aparición de la propiedad estatal liberada al capital petrolero privado.

La industria petrolera norteamericana nos muestra como la propiedad privada de la tierra se presenta como una importante barrera para la acumulación del capital petrolero en dicho país. La estatización pareciera ser aquí como una necesidad para disolver dichas barreras. Sin embargo, la estatización, en la medida en que avanza sobre la propiedad privada, cuestiona la propia existencia de la clase capitalista. De allí que el camino para la estatización, lejos está de ser una simple medida administrativa, sino que supone un avance general de la lucha de clases. ${ }^{3}$ Ahora bien, la industria petrolera nos presenta casos, de hecho la mayoría, donde la propiedad de la totalidad de los yacimientos de un país comienza estando en manos del estado. Estos casos parecieran presentar la solución ideal para el capital petrolero. Sin embargo, el desarrollo de la propiedad estatal de los yacimientos encierra nuevas contradicciones.

La acumulación de capital constituye un proceso mundial, pero no comienza tomando tal forma concreta inmediata. Por el contrario, toma la forma de una confluencia de espacios nacionales que parecieran ser en sí mismos unidades íntegras del capital social. Sin embargo, no dejan de ser más que fragmentos, que necesariamente compiten entre sí, de un mismo capital social (IÑIGO CARRERA, 2008, p. 148-149). En consecuencia, entendemos que la aparición de la propiedad estatal de la tierra no supone de por sí una resolución inmediata de la contradicción general inmanente entre capitalista y quien ejerce la personificación de la tierra, en este caso el Estado.

Aun bajo dominio estatal, la propiedad de los yacimientos queda acotada a un espacio nacional de acumulación, cuyos capitales deben entrar en competencia con capitales de otros espacios nacionales. En este sentido, a medida que en estos países se desarrolla la acumulación de capitales fragmentados que apuntan a apropiar renta dentro del mercado interno, la propiedad estatal destinada originalmente a liberar al capital petrolero de las trabas que impone la propiedad privada puede terminar transformándose en su opuesto. En consecuencia, pasar a comportarse como una propiedad que presente las limitaciones propias de la propiedad privada, desde la perspectiva del proceso mundial, reestableciendo nuevas

3 Aparte de los Estados Unidos, sólo dos países presentaron la forma de propiedad privada. En ambos casos la tierra petrolera terminó siendo estatizada en marcos de ascenso de la lucha de la clase obrera. Nos referimos a la Rusia zarista y México. 
formas de mayor presión rentística al transformarse en un atributo privado de los capitales que operan al interior del espacio nacional. ${ }^{4}$

Tanto en Venezuela como los países petroleros de Medio Oriente comienzan su producción a comienzos de siglo XX con regímenes de propiedad que liberan al capital petrolero de tener que enfrentarse a restricciones vinculadas al fraccionamiento de la tierra, así como también al pago de cánones de renta elevados. De hecho, durante las primeras décadas del pasado siglo, los países de Medio Oriente todavía gravaban a las actividades petroleras con impuestos que dependían de la magnitud de superficie explotada, en abstracción de la masa de producto (BINA, 2011; MOMMER, 1988; AL-CHABALI, 1984).

Luego de la Segunda Guerra Mundial, a medida que la economía capitalista mundial iniciaba una nueva fase expansiva, la sobreproducción provocada por la crisis de 1930 quedaba en el pasado y las regiones que hasta hoy son las más productivas del mundo (en particular Medio Oriente) comenzaban a desarrollarse a tasas aceleradas, a la vez que la predominancia de la producción norteamericana comenzaba a decaer. Si para finales de la década de 1920 ésta representaba el $74 \%$ de la producción mundial, para 1950 este porcentaje se reduciría a un $48 \%$. Para 1970 sólo representaba el 21\% y en la actualidad no supera el 8\% (ENERGY INFORMATION ADMINISTRATION, 2014; ZANDEN, 2007, p. 49). A su vez, para 1947 la situación de Estados Unidos como un país exportador quedaba en el pasado, pasando a convertirse en un importador neto de crudo.

En esta nueva fase, las medidas aplicadas durante los años de crisis comenzaban a erosionarse. Por un lado, las mismas compañías que habían acordado no expandir sus actividades en Medio Oriente eran las primeras en violar dicho acuerdo. Por otro lado, se establecían modificaciones en los regímenes existentes que fijaban los precios del crudo. Sin entrar en detalles acerca de cómo se establecieron los distintos sistemas de fijación de precios, cabe remarcar que en tanto se determinaban como precios de transferencias establecidos administrativamente por las compañías privadas, a medida que el crudo de Medio Oriente debía avanzar cada vez más hacia occidente, las diferencias de transporte se descontaban del precio FOB, erosionando los precios sobre los cuáles los estados de los países productores fijaban sus gravámenes (PARRA, 2004). En consecuencia, los países productores veían como, a pesar de que el mundo demandaba cada vez más petróleo de Medio oriente, sus precios tendían a reducirse producto de los sistemas existentes de fijación de precios. Es así que comenzaron a acrecentarse los conflic-

$4 \quad$ El problema de la transformación de la propiedad estatal libre en propiedad nacional y su lugar en la determinación de la renta es pasado por alto por la bibliografía que analiza el desarrollo de la industria petrolera, salvo por Mommer $(1988,2003)$ quien reconoce esta diferenciación en una serie de valiosos trabajos destinados a analizar las formas concretas que fue adoptando el ejercicio de la propiedad territorial en distintos países. 
tos con las compañías internacionales. Conflictos impulsados por las necesidades de los capitales que operaban en los mercados internos de dichos países.

El crecimiento de la renta petrolera apropiable por los países exportadores, aun con las limitaciones mencionadas, dio lugar a un acelerado desarrollo de la industria no petrolera (ver Gráfico 4) que demandaba crecientes masas de renta para subsidiar y sostener sus actividades orientadas al mercado interno (DACHEVSKY, 2011b). Luego, esta economía no petrolera mercado-internista dará los fundamentos necesarios para avanzar sobre las compañías internacionales. A su vez, a medida que la renta generaba una expansión del mercado interno, la creciente competencia entre las propias compañías arrendatarias dará a los gobiernos de los países productores la fuerza necesaria para intervenir de manera decidida en el negocio.

Hacia la finalización de la Segunda Guerra Mundial, la casi totalidad de la producción mundial era realizada por siete empresas, comúnmente conocidas como las Siete Hermanas. ${ }^{5}$ Estas empresas cuyo dominio era casi absoluto durante los años posteriores a la crisis del treinta, comenzarían a perder poder desde la década de 1960 a partir de la incorporación de nuevas empresas y la expansión de la producción soviética. Luego de finalizada la Segunda Guerra Mundial, hacia 1950, las "siete grandes" en conjunto representaban el 98,3\% del mercado mundial excluyendo a Estados Unidos y los países socialistas. Luego en 1957, la participación de éstas seguía siendo dominante pero había descendido al 89\%. Hacia 1969, antes de que comenzara a revertirse la tendencia descendente del precio del crudo, era del 76,1\% (GRIFFIN; TEECE, 1982, p. 4-5).

En este contexto, los conflictos no se hicieron esperar. Ya en 1947 el gobierno iraní decidía impulsar una investigación para revisar las condiciones bajo las cuales operaba la Anglo Iranian Oil Company (British Petroleum). A partir de esta investigación, el gobierno iraní cotejó las condiciones existentes en Venezuela e Irán y dio cuenta de que si en su país hubiesen existido las mismas leyes que en Venezuela en 1947 habría podido recaudar una suma tres veces superior a lo efectivamente recaudado. La principal diferencia residía en el hecho de que mientras en Venezuela el impuesto a la actividad petrolífera se calculaba antes del pago de impuestos de la compañía en su país de origen, en Irán se calculaban después. Es decir, el margen sobre el cual el gobierno iraní podía aplicar su impuesto era el resto que quedaba luego de que ser gravado por el gobierno británico. Lo cual, permitía que fuese el gobierno británico el que apropiase el grueso de la renta petrolera iraní. De esta forma, en 1933 el gobierno inglés recibía por impuestos a

$5 \quad$ Estas eran, la Standard Oil de New Jersey (actualmente ESSO o EXXON, depende el país), la Royal Dutch Shell (actualmente Shell, luego de que se fusionaran la Royal Dutch y la Shell), la Anglo Iranian Oil Company (hoy denominada British Petroleum), la Standard Oil de New York (que hoy se conoce como Mobil y se fusionó EXXON), la Standard Oil de California (Chevron), la GulfCorporation (adquirida por Chevron) y Texaco (que también sería fusionada con Chevron). 
la Anglo Iranian un 11\% más de lo que recibía el gobierno iraní. En 1947 esa diferencia se había ampliado y el gobierno inglés recibía un $2.000 \%$ más que el iraní (MOMMER, 1988, p. 123).

Entre 1948 y 1949, Irán decidía revertir la situación y modificaba las condiciones para la explotación de las reservas. En principio se elaboraba una propuesta que se inspiraba en el esquema venezolano y consistía de una serie de impuestos que debían dar como resultado para el gobierno una apropiación del 50\% de la ganancia bruta (es decir, antes de los impuestos del gobierno inglés). Este esquema se lo conoció como fifty-fifty y se extendería hacia otros países de Medio Oriente. Sin embargo, esta propuesta nunca llegó a aprobarse. Antes de que comenzara a negociarse este esquema el gobierno de Mosadeq resolvía la nacionalización. En la medida en que rompía con el monopolio inglés, advierten Mommer (1988) y Rivero (1979), la nacionalización fue bien vista por los capitales norteamericanos, quienes la veían como una oportunidad para llegar a un arreglo en la región. En consecuencia, hacia 1953, lo que antes era un monopolio absoluto de la Anglo Iranian (British Petroleum) quedaba repartido de la siguiente manera: un 40\% para la British Petroleum, un consorcio de compañías norteamericanas controlaría otro 40\% (Standard Oil de New Jersey, Standard Oil de California, Texaco, Gulf y Standard Oil de New York, entre otras), Shell se quedaría con un 14\% y la CompagnieFrançaise des Pétroles el 6\% restante (HOWARTH; JONKER, 2007, p. 175). Luego, se estableció una repartición de la ganancia de 50:50 para todas.

La repartición del 50:50 no era del todo mal vista por las compañías. En realidad perjudicaba más a la recaudación de los gobiernos norteamericanos e inglés que a las propias empresas. Esto sin contar que, para entonces, un arrendamiento del 50\% era similar a la tasa que se pagaba en los Estados Unidos por los yacimientos de más baja productividad (MOMMER, 1998, p. 134). En definitiva, el fifty-fifty se encargaba de generalizar una tasa de renta sin tener en cuenta la diferencia de productividad. En este sentido, las compañías no tardaron en aceptarlo y el esquema se extendería rápidamente hacia otros países como Arabia Saudita (1950) y Kuwait (1951).

Así como las Siete Hermanas fueron impotentes para congelar la competencia en el mercado de crudo y de derivados, también lo fueron para evitar la competencia en el arrendamiento de tierras. En 1957, la italiana Ente Nationale de Idrocarburi (ENI) le ofertaba al Sha de Irán una repartición de 25:75 (25\% para la empresa y 75\% para el gobierno iraní) a cambio de una concesión petrolera en el país. A pesar de la oposición de las hermanas, el contrato se terminaría firmando y nuevas compañías "independientes" ingresarían a la región. En Arabia Saudita sucedería algo similar cuando un grupo japonés obtuvo una concesión basada en una repartición de 46:54. Al mismo tiempo que la competencia hacía caer el precio del crudo, empujaba hacia arriba el precio del arrendamiento. 
La extensión del fifty-fifty tuvo otra consecuencia no programada: alineó a todos los países de Medio Oriente y a Venezuela en lo referido al problema de la renta. Este alineamiento comenzó a ponerse en mayor evidencia en 1959, luego de que se firmara el Pacto de Caballeros en El Cairo por el cual los países formarían una comisión de consulta para discutir problemas comunes como la renta, establecimiento de contratos con nuevos países, precios, etc. Este pacto terminó quedando como un antecedente inmediato de una instancia de colaboración mayor. La formación, en 1960, de la Organización de Países Exportadores de Petróleo (OPEP). ${ }^{6}$

El propósito de avanzar en el control de la producción tuvo su correlato en la creación empresas nacionales mixtas: Irán (1954), Venezuela (1960), Kuwait (1960), Arabia Saudita (1962), Argelia (1963), Irak (1965) y Libia (1969). De todas formas, durante estos años, las acciones de la OPEP se concentraron más en el aspecto fiscal y de coordinación entre países productores para controlar la producción de crudo (CHEVALIER, 1974).

La determinación del precio del barril será el centro de disputas posteriores que conducirán a una mayor injerencia de los gobiernos de los países petroleros en la producción y, finalmente, a la crisis de 1973-1974 y el pasaje de activos petroleros privados a manos de las compañías nacionales existentes. La creciente injerencia de la OPEP en el mercado del crudo comenzaría a efectivizarse con claridad dese 1971 cuando la tendencia a la caída de precios, que ya arrastraba más de 20 años, mostraba signos de revertirse. Luego, en 1974 se triplicaba en forma abrupta pasando de los u\$s12,87 a los u\$s54,74 para luego dar un nuevo salto a en 1979 cuando alcanzaría los u\$s101,43-todo en dólares de 2013- (BP, 2014). Estas subas de precio permitirían un súbito aumento de la renta petrolera apropiable por los países de la OPEP (Gráfico 1). ${ }^{7}$

6 Al momento de su formación la OPEP estaba compuesta por Irán, Irak, Kuwait, Venezuela y Arabia Saudita. Luego, entre 1960 y mediados de la década de 1970, se fueron incorporando más países (Qatar, Indonesia, Libia, Emiratos Árabes Unidos, Argelia y Nigeria). Cabe señalar que la incorporación posterior de dichos países se explica por el hecho de que el objetivo de la OPEP era, en definitiva, establecer controles a la producción para evitar el exceso. Lo cual, no resultaba atractivo para países como Argelia o Nigeria que recién comenzaban a incrementar sus exportaciones de crudo.

7 Las distintas formas que tomaron los procesos de nacionalización, sean del 100\% como en Venezuela o parciales como en Arabia Saudita nos resultan indiferentes al proceso que estamos describiendo por el cual aumenta, en términos generales, la renta percibida por dichos países. La forma de la nacionalización no cambia el contenido en lo referido al manejo de la renta. Cabe señalar que las distintas formas que tomaron las nacionalizaciones responden, en muchos casos, a las diferentes posibilidades de poder continuar, luego de nacionalizada la empresas, las operaciones con normalidad. Por ejemplo, en países como Arabia Saudita, la nacionalización gradual habría tenido como finalidad el poder conservar la mano de obra calificada, que de otro modo hubiera perdido (MARCEL, 2006, p. 130). Tampoco consideramos relevante en este punto el pago de indemnizaciones por dichas nacionalizaciones. De ninguna manera se puede afirmar seriamente que el pago de indemnizaciones compensa la mayor renta recibida. Por ejemplo, en el caso venezolano, donde la indemnización debió cancelar una nacionalización completa, el pago 
Gráfico 1 - OPEP. Valor de exportaciones de petróleo (1960-2013)

Millones de u\$s (PPI $2010=100)$

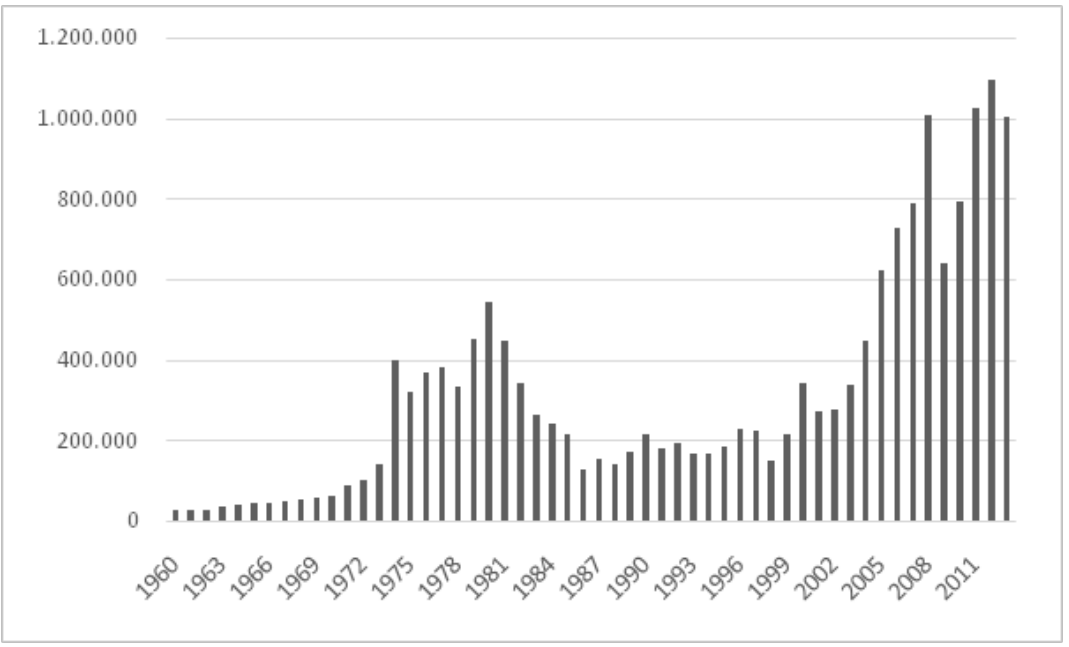

Fuente: Elaboración propia en base a fuentes diversas. Producción: OPEP (2014); Producer Price Index en BLS.

\subsection{Crisis y Reestructuración}

La crisis y las nacionalizaciones desatarán una reestructuración en la industria petrolera mundial. Al respecto nos interesa remarcar tres puntos principales:

En primer lugar, la recuperación del horizonte de reservas de la OPEP y la puesta en producción de nuevas áreas petroleras (Gráfico 2). Durante toda la década de 1960, los países de la OPEP no sólo veían como el precio de exportación de su petróleo caía aunque su petróleo era cada vez más demandado, sino que la vida útil de sus reservas se reducía de manera drástica debido a la sobreexplotación de sus yacimientos. Si para 1960, las reservas de la OPEP cubrían 80 años de exportaciones, para 1972, solo cubrían 50. La suba de precios expresaría la posibilidad de poner en producción áreas del planeta más cotosas que cubrirían una mayor parte de la demanda global. En consecuencia, es de remarcar que a partir de la llamada crisis, tanto la participación de las reservas de la OPEP dentro del total mundial, como su participación en la producción y su vida útil, se mantendrían estables.

realizado alcanzó sólo los 1.000 millones de dólares (MOMMER, 1989, p. 253). Cabe recordar que el valor de las exportaciones venezolanas sólo entre 1972 y 1974 se incrementó en más de 8.000 millones de dólares (ORGANIZATION OF THE PETROLEUM EXPORTING COUNTRIES, 2014). 
Gráfico 2 - Participación de las reservas y exportaciones de petróleo provenientes de la OPEP en el mercado mundial y relación reservas/exportaciones (1960-2013)

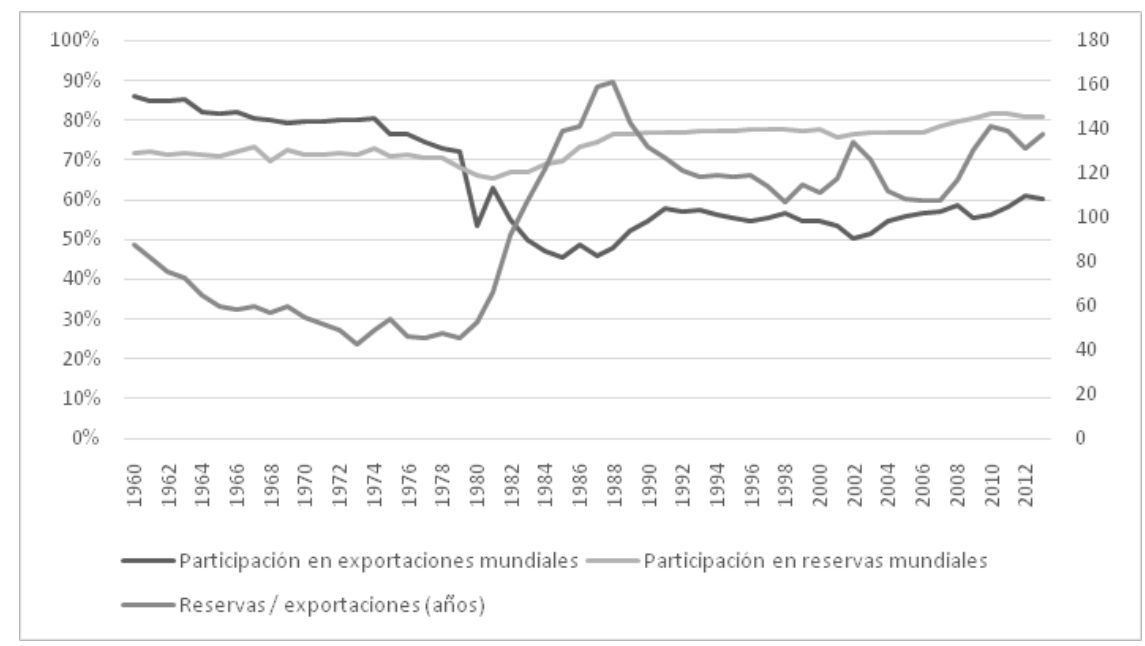

Fuente: Elaboración propia en base a OPEP (2014).

En segundo lugar, la puesta en producción de nuevas áreas requería un cambio en la forma en que se fijaban los precios. Hasta finales de los años ' 70 , su fijación por contratos de venta plazo era la forma dominante (precios posted). Estos precios se fijaban de manera administrativa como precios de transferencia entre unas pocas empresas que de esta manera buscaban radicar sus ingresos allí donde era impositivamente más conveniente (AL-CHABALI, 1974; DACHEVSKY, 2011 a). Lo cual traía como consecuencia una notable disparidad internacional de precios de exportación (ver Gráfico 3). En paralelo, existía un mercado centrado en Rotterdam en donde los productores podían vender crudo por fuera de la forma tradicional de contratos de largo plazo, al mismo tiempo que las refinarías contaban con un lugar de abastecimiento de emergencia ante una imprevista falta de crudo. Este mercado sería comúnmente conocido como mercado spot. A comienzos de la década, el mercado spot solo representaba entre el 1 y el $2 \%$ del intercambio comercial de crudo. El estallido de los precios del ' 73 condujo a ciertas compañías a prevenirse de contratos de largo plazo, lo cual incentivó las operaciones diarias en el mercado spot. De todas formas, hacia 1978 este mercado apenas había alcanzado el 3 o 4\% del conjunto de las transacciones. Luego de la guerra entre Irán e Irak que motivó la "segunda crisis del petróleo", el mercado spot volvería a crecer llegando a representar un $10 \%$ de las transacciones totales. Dado que el precio del mercado spot tendía a ser más elevado que el posted (por ser hasta entonces un mercado de emergencia), los países productores comenzaron a redirigir sus transacciones a dicho mercado, y para los años ' 80 la OPEP comenzaría a utilizar 
el precio spot como referencia oficial para sus cálculos (MAUGERI, 2006). En otras palabras, la crisis daría comienzo a la formación de un mercado autónomo de crudo con precios que se igualan a nivel mundial. ${ }^{8}$ En el Gráfico 3 puede observarse, a partir del caso venezolano, como se estabiliza, luego de la llamada "crisis del petróleo”, la evolución del precio de exportación del crudo de dicho país respecto del precio internacional.

Gráfico 3 - Participación de las reservas y exportaciones de petróleo provenientes de la OPEP en el mercado mundial y relación reservas / exportaciones (1960-2013)

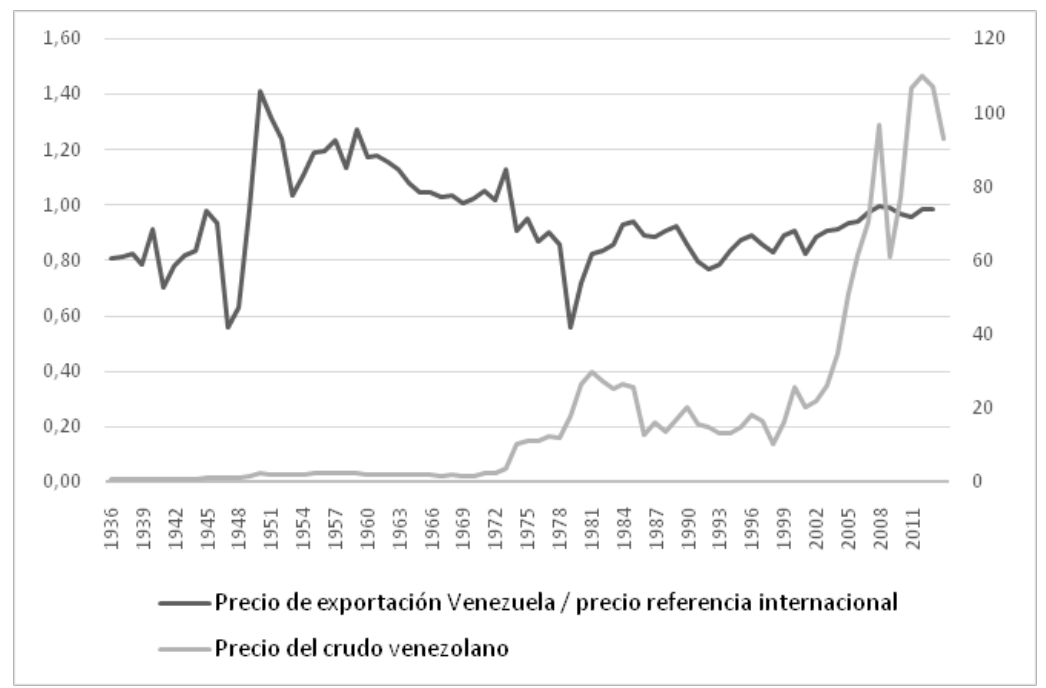

Fuente: Elaboración propia en base a fuentes diversas. Serie de precio de crudo venezolano en base a Baptista (2006) y EIA. Referencia internacional en base a British Petroleum (2014).

$8 \quad$ Autores como Bina (2011), en su afán por demostrar que la crisis de 1973 no fue un simple shortage internacional, reconocen esta transformación en la fijación de precios pero la conciben como el pasaje de estructuras regionales a una estructura global de valor (BINA, 2011, p. 4). Es decir, no como un cambio en el modo en que se desenvuelve el proceso mundial de acumulación de capital, sino como un cambio que da lugar al surgimiento del mismo. De este modo, la crisis de 1973 sería el resultado de una transición hacia el desarrollo capitalista en la industria petrolera (BINA, 2011, p. 30) que se consolidaría cuando dicha industria se transformó finalmente en un todo orgánico (BINA, 2011, p. 35). Más allá de lo erróneo de caracterizar a la industria petrolera pre 1973 como no integrada, cuando de hecho se encontraba más integrada que en la actualidad, el planteo de Bina presenta dos grandes problemas. El primero es que encara la cuestión de la fijación de precios en abstracción del proceso por el cual el plus valor se transforma en renta. Es decir, no concibe a la fijación de precios como un curso de apropiación por el cual efectivamente se le escapaba renta petrolera a los países productores (DACHEVSKY, 2011). El segundo problema es más general y remite a una confusión propia de muchos economistas marxistas que en función de discutir las teorías del capital monopolista ponen excesivo énfasis en la persistencia del acto de competencia en el mercado. Es decir, terminan confundiendo lo específico del proceso de valorización con la forma que adopta en el proceso de circulación. De esta manera, cuando Bina se enfrenta a formas de la circulación donde los precios aparecen efectivamente fijados de manera administrativa, no le queda otra alternativa que afirmar que allí no hay suficiente capitalismo. 
Por último, la formación de un mercado competitivo de crudo tuvo como condición necesaria la fragmentación de la industria petrolera internacional. Las nacionalizaciones rompieron la integración vertical que disponían las llamadas hermanas. Es decir, de la crisis surgirá una industria petrolera internacional dividida en dos grandes polos. Por un lado, las tradicionales compañías internacionales que ahora pasan a controlar los procesos aguas abajo (transporte, refinación y comercialización) pero necesitadas de acceder al control de reservas. Por otro lado, compañías nacionales que controlan las principales reservas petroleras del mundo pero que no disponen de ningún control sobre el circuito posterior a la extracción. Esta situación dio lugar a que se ponga en marcha un nuevo proceso de reintegración internacional.

En primera instancia, la restructuración desencadenó un acelerado proceso de centralización de capital en el plano aguas abajo. Proceso que no fue de la mano de una ampliación de la capacidad total de refinación, sino por una centralización en cada vez menos manos de la capacidad existente. Es decir, desde 1974 en adelante se observa el cierre muchas de refinerías que se compensa por la ampliación de la capacidad de las que permanecen. Por ejemplo, en 1974 se encontraban 273 refinerías en operación en los Estados Unidos, mientras que en 2010 esa cifra se redujo a 148, mientras que la capacidad total se mantuvo relativamente estable (EIA). De hecho, desde finales de la década de 1970 que no se construyen nuevas refinerías en los Estados Unidos (MURRAY; KISHAN, 2005).

Dicho proceso de centralización de la refinación no será ajeno a los países de la OPEP. Por el contrario, estos participarán de manera activa adquiriendo refinerías, total o parcialmente, en los países consumidores. Según el estudio de Al-Moneef (1998) ya para mediados de la década de 1990, Irán controlaba una refinería en el exterior (India), Kuwait controlaba tres (Italia, Dinamarca y Holanda), Libia controlaba cuatro (Italia, Alemania, Suiza y Grecia), Arabia Saudita controlaba seis (una en Corea, una en Filipinas, una en Grecia y tres en Estados Unidos) y Venezuela, que fue uno de los pioneros, controlaba dieciséis (una en Bahamas, seis en Estados Unidos, cuatro en Alemania, una en Bélgica, dos en Suecia y dos en Reino Unido).

La compra o participación en refinerías del exterior por parte de la OPEP tiene varios propósitos. Por un lado, permite controlar la colocación de crudo en mejores condiciones, en un contexto en que la mayor participación del crudo extra OPEP acentúa la competencia. A su vez, les permite adaptar los procesos de las refinerías para hacerlos más aptos a las cualidades de los crudos de cada país. Lo cual, constituye una manera de valorizar el petróleo extraído por la propia compañía nacional. 


\section{Internacionalización y Límites a la Propiedad Nacional}

Cuando se estudia el desempeño de compañías petroleras estatales pareciera inevitable buscar analizarlas en función de la eficiencia que alcanzan en comparación al capital privado. En este sentido, Wolf (2008) realizó uno de los estudios más sistemáticos en esta perspectiva, a partir de información de las 50 compañías privadas y estatales más importantes del mundo durante los últimos veinte años. Allí busca demostrar que, al fin y al cabo, las compañías privadas son más eficientes que sus contrapartes estatales, salvo las compañías de la OPEP donde, en su rendimiento influye de manera significativa el volumen de sus reservas. Teniendo en cuenta esta distorsión el autor concluye que las compañías de propiedad pública tienen un manejo más conservador de sus reservas.

En efecto, las compañías nacionales de petróleo tienden a una extracción menos intensiva de sus reservas. Sin embargo, no consideramos que esto pueda reducirse a una diferente eficiencia de management en abstracto, sino del hecho de ser compañías que al mismo tiempo que actúan como capitales, deben hacerlo como guardianes del suelo explotado y como sostenes de la generalidad de los capitales que actúan dentro de sus espacios nacionales. El objetivo de dichas compañías difiere sustancialmente del de las compañías privadas. Mientras las primeras apuntan a garantizar la mayor captación posible de renta dentro del espacio nacional, las segundas tienen como preocupación fundamental extraer la mayor cantidad de crudo posible dentro del plazo de la concesión/contrato que rige sus operaciones. Con esto queremos enfatizar en que el desempeño de las compañías petroleras no puede ser analizando en abstracción del problema de cómo se ejerce la propiedad de la tierra. Es decir, en función de lo desarrollado en la sección anterior, lo que debe ser analizado al momento de estudiar a las compañías nacionales no es su eficiencia en sacar la mayor cantidad de crudo en el menor lapso posible, sino su capacidad para captar la mayor cantidad de renta petrolera internacional y distribuirla para el sostenimiento de los capitales que operan en su interior apropiando renta.

Ahora bien, si como señalamos anteriormente el desarrollo de la propiedad nacional condujo a la nacionalización de compañías, podemos observar que el desarrollo de dichas compañías las está conduciendo a reintegrar los eslabones rotos por la crisis, avanzando en la internacionalización. Luego, así como la necesidad de colocar el crudo en el mercado internacional las impulsó a adquirir activos en el exterior, la necesidad de mantener la vida útil de sus propias reservas las está llevando a garantizar una presencia cada vez mayor de las compañías internacionales en el plano de la exploración-extracción. Las razones de esta mayor presencia del capital extranjero son distintas en cada país, pero conjugan la necesidad de acceder a tecnologías y conocimientos en la aplicación de mecanismos 
más sofisticados para el desarrollo de reservas (los cuales fueron desarrollados por las compañías que se encargaron de hacer expandir la producción en las regiones fuera de la OPEP) y la falta de capacidad de financiamiento por parte de compañías nacionales que deben ceder una sustancial parte de sus ingresos a financiar los capitales no petroleros que operan en sus países (MARCEL, 2006; HIRSCH, 2008). El propio pequeño capital, de escala restringida al mercado interno apropiando renta petrolera, que décadas atrás aparecía como el impulsor de la nacionalización, ahora se pone en evidencia como un lastre cada vez más insostenible. Es decir, como capitales que nunca tuvieron la potencialidad de transformarse en capitales medios. La evidencia de esta limitación se registra en los gráficos siguientes donde observamos, a pesar del crecimiento sostenido del producto industrial (Gráfico 4), una irregular evolución de la productividad en términos absolutos (mostrando fases de ascenso y descenso en el caso de Irán y de estancamiento e incluso caída en Venezuela y Arabia Saudita - Gráfico 5) y un sostenido retroceso en términos relativos a la economía que contendría a los capitales medios que acumulan a la tasa normal de ganancia (Gráfico 6). En consecuencia, no nos sorprende que la forma de representación ideológica por excelencia de estos pequeños capitales haya dejado de ser el nacionalismo petrolero, para ser la "maldición de los recursos naturales" (DACHEVSKY, 2011b).

Gráfico 4 - Evolución del producto manufacturero en países seleccionados de la OPEP (1960-2013) $1968=1$

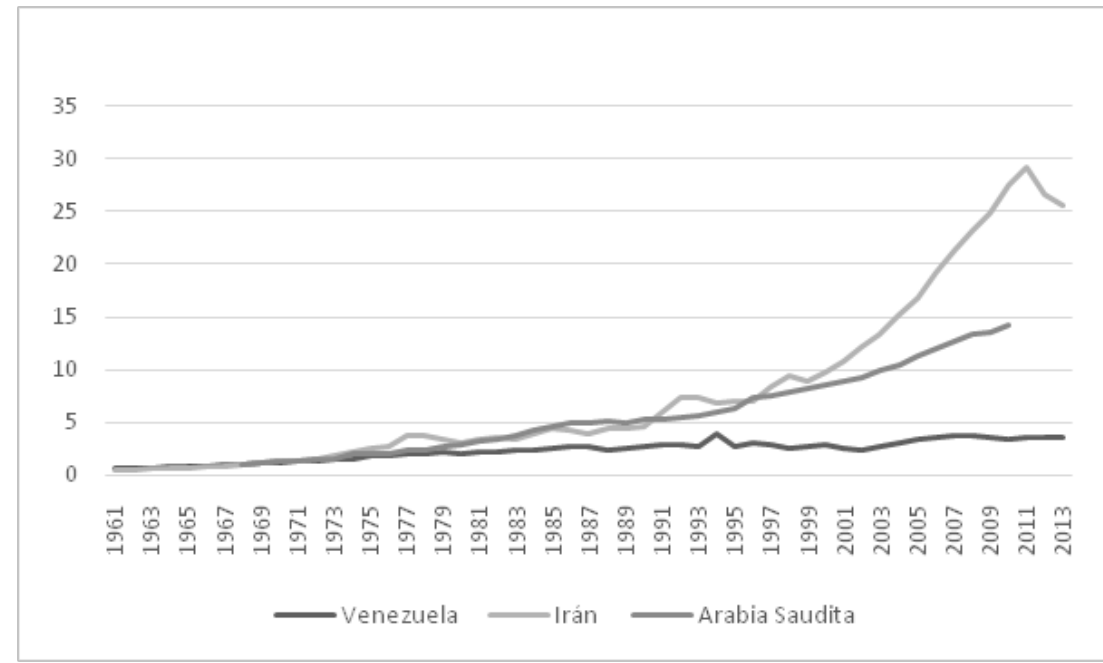

Fuente: Elaboración propia en base a fuentes diversas. Venezuela: Baptista y BCV; Irán: CBI, World Bank y United Nations Industrial Development Organization; Arabia Saudita: World Bank y United Nations Industrial Development Organization. 
Gráfico 5 - Evolución de la productividad industrial por obrero en países seleccionados de la OPEP (1961-2013)

$$
2000=1
$$

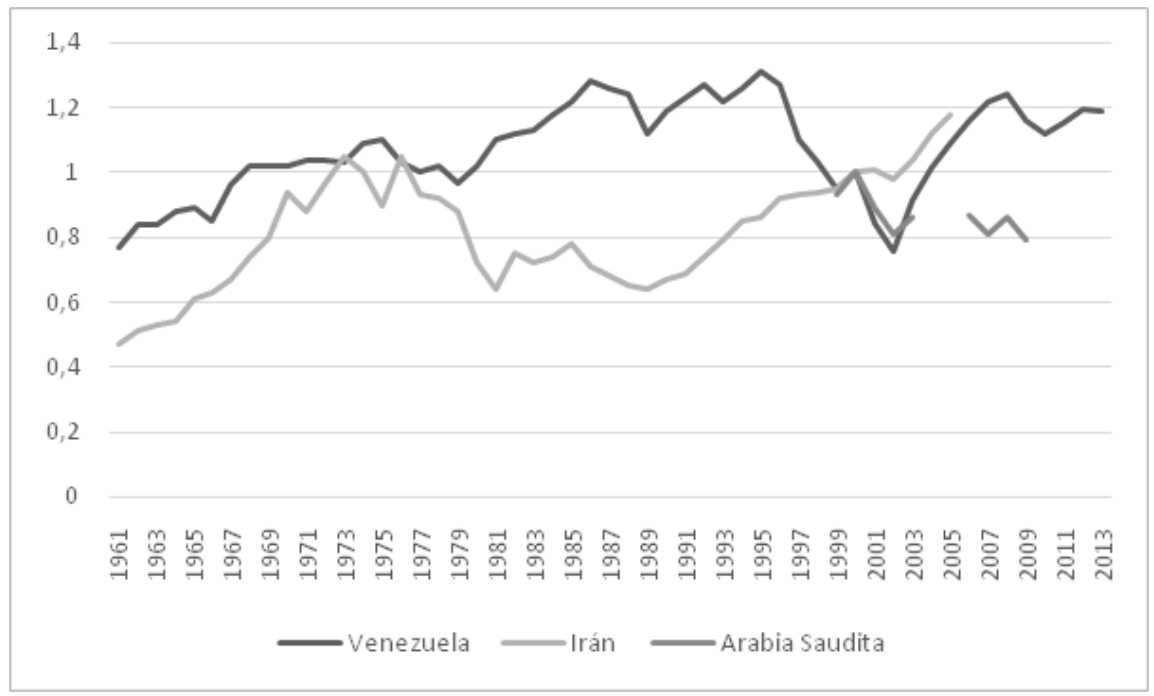

Fuente: Elaboración propia en base a Gráfico 4.

Gráfico 6 - Evolución de la productividad industrial por obrero en países seleccionados de la OPEP relativa a Estados Unidos (1961-2013)

$$
2000=1
$$

Fuente: Elaboración propia en base a Gráfico 4 y productividad de Estados Unidos en base a BLS. 
A medida que las compañías nacionales se internacionalizan, sus intereses parecen confundirse cada vez más con los de las compañías internacionales. En la actualidad, a diferencia de la década de 1970, ambas tienen activos embargables en el extranjero. Las nuevas relaciones internacionales entre compañías y países productores se han expresado jurídicamente en la firma de tratados bilaterales y multilaterales de inversión donde se establecen pautas que limitan cada vez más el ejercicio de la propiedad nacional.

Esta clase de acuerdos comenzaron a generalizarse a partir de la firma de Tratados Bilaterales de Inversión (TBI) entre grandes países consumidores y países de la ex URSS con disponibilidad de recursos naturales pero desesperados por atraer inversión extranjera. Con la caída de la URSS, sus ex países miembros comenzaron a firmar TBI en su mayor parte con los países europeos de la OECD. Luego, la expansión de los TBI condujo a que en 1991 se redactara la Carta Europea de Energía (CEE). La cual, se proponía como un ámbito multilateral que reemplazaría la firma de tratados bilaterales. Si bien la CEE no tenía un carácter vinculante, sirvió de antecedente para el Tratado de la Carta de Energía (TCE) firmado en 1994. El TCE aparece con el objetivo darle un marco legal al intercambio mercantil y al flujo internacional de inversiones en materia energética. Resultado de tres años de negociaciones luego de firmada la CEE, a diferencia de ésta, el TCE supone obligaciones legales para los países miembros. Es un acuerdo de protección de la inversión que posee un sistema de solución de controversias de carácter vinculante.

Desde su creación, el TCE presentó modificaciones y la incorporación de nuevos países miembros. Si bien, todavía no ha logrado colocarse como un regulador ineludible para la generalidad de los países exportadores de petróleo, de manera en que lo es la Organización Mundial de Comercio para la generalidad de las mercancías, constituye una muestra de las nuevas relaciones internacionales en materia energética. El TCE todavía no cuenta con los países de la OPEP como miembros, cuya incorporación se encuentra en proceso de negociación. Sin embargo, nos parece importante de analizar dado que la mayor parte de su contenido, salvo algunos artículos puntuales que tienen que ver con una mayor amplitud del tratado en función de su carácter multilateral, es idéntico a los artículos comprendidos en los TBI energéticos que los propios países de la OPEP todavía siguen firmando de manera individual. Es decir, que los países de la OPEP firman acuerdos que históricamente han servido de antecedente a la creación del TCE. En este sentido, nos interesa remarcar una serie de puntos centrales que figuran en el TCE y aquellos que ya vemos aparecer en los TBI firmados por países de la OPEP.

Tanto los TBI como el TCE plantean que su objetivo no es definir la orientación de la política energética, en tanto decisión soberana de cada país, sino plantear un marco de no discriminación en el tratamiento de las inversiones. Lo cual, apa- 
rece condensado en la exigencia de trato nacional. Es decir, en que se garantice que el inversor extranjero no sufra medidas discriminatorias respecto de las recibidas por inversores nacionales. El significado de trato nacional se extiende al trato recibido por los inversores nacionales en terceros países como referencia para fijar el trato del inversor extranjero en el propio país. ${ }^{9}$

Ahora bien, no sólo se busca garantizar el trato nacional, sino también pautas que van más allá de la cuestión de la no discriminación, proponiendo normas que apuntan a satisfacer intereses específicos de la inversión transnacional. Uno de estos puntos refiere a la cuestión al origen de la mano de obra, insumos y tecnología empleada en la producción. Respecto del empleo de mano de obra en posiciones jerárquicas, el artículo 11 del TCE establece que no pueden aplicarse restricciones al empleo de mano de obra proveniente del extranjero. Otra cláusula de esta clase, aunque quizás más relevante, establece un criterio similar respecto del uso de tecnología (artículo 8). A partir de la cual, los gobiernos no pueden poner trabas al uso de tecnología proveniente del exterior, en beneficio de uso de tecnología nacional. ${ }^{10}$ De conjunto estas dos medidas limitan la posibilidad de exigir pautas de compre nacional en los países productores. Cabe recordar que las medidas de compre nacional son mecanismos por excelencia de transferencia de renta hacia el mercado interno. Si bien, esta clase de cláusula está presente en el TCE y en los TBI firmados por los países de la ex URSS, como es el caso del TBI entre Azerbaiyán y Estados Unidos, ${ }^{11}$ no aparece todavía, en los TBI firmados los países de la OPEP.

Otro punto fundamental para el capital extranjero es la posibilidad de transferir divisas al exterior. En este sentido, el artículo 14 del tratado se encarga de proporcionarle total libertad, quitando al gobierno del país local la posibilidad de poner trabas a la transferencia. ${ }^{12}$ A su vez, se garantiza no sólo la posibilidad de

9 "El TCE establece que una inversión hecha por un inversor de otra Parte Contratante debe ser tratada no menos favorablemente que la inversión de los inversores nacionales o que la de los inversores de cualquier país tercero. Fuera de las excepciones normales, por ejemplo por razones de seguridad nacional, la única excepción específica de esta regla concierne los impuestos directos; en este caso, la equidad requiere que la tributación del país sea tomada en consideración. Esta regla de conceder "trato nacional" también se aplica a las inversiones de cartera, lo que tranquiliza a los que desean adquirir acciones de una empresa controlada por una compañía nacional." (TRATADO SOBRE LA CARTA DE ENERGÍA, 1994, p. 9).

10 "las Partes Contratantes eliminarán los obstáculos existentes y no crearán otros que afecten a la transferencia de tecnología en el campo de las materias y productos energéticos y los equipos y servicios correspondientes, con sujeción a las obligaciones de no proliferación y a otras obligaciones internacionales." (TRATADO SOBRE LA CARTA DE ENERGÍA, 1994, art. 8).

11 "Neither party shall mandate or enforce, as a condition for the establishment, acquisition, expansion, management, conduct or operation of a covered investment, any requirement [...] to achieve a particular level or percentage of local content, or to purchase, use or otherwise give a preference to products or services of domestic origin or from domestic source" (AZERBAIJAN-USA, 2000, art. 6).

12 “Las Partes Contratantes garantizarán, con respecto a las inversiones realizadas en su territorio por inversores de cualquier otra Parte Contratante, la libertad de las transferencias a su territorio y fuera de él, incluidas las transferencias: a) del capital inicial más el capital adicional para el mantenimiento y desarrollo de una inversión; b) de los rendimientos; c) de los pagos resultantes 
transferencias, sino que dicha posibilidad no se vea trabada por regímenes cambiarios vigentes en cada país. ${ }^{13}$ Estas cláusulas se encuentran también en todos los TBI firmados por países de la OPEP.

Una de las disposiciones más importantes tanto dentro del TCE como en los TBI acordados por países de la OPEP es aquella que protege al inversor extranjero frente a la posibilidad de una expropiación. Dado que la expropiación aparece en las legislaciones nacionales como una posibilidad en casos de interés público, ésta es contemplada, pero se establece que deberá realizarse "de manera no discriminatoria” (TRATADO SOBRE LA CARTA DE ENERGÍA, 1994, art. 13, punto 1.b). Es decir, manteniendo el principio de trato nacional. A su vez, se establecen disposiciones que buscan proteger al inversor en lo referido al pago de indemnizaciones pertinentes y a la forma en que éstas deben ser estimadas. La libre y pronta disposición del monto correspondiente a la indemnización aparece garantizada en el artículo 14, mencionado anteriormente. Respecto de la estimación, el artículo 13 busca proteger al inversor de una posible desvalorización de la inversión desde el momento en que se hace pública la posibilidad de una expropiación hasta que ésta se haga efectiva. ${ }^{14}$

Uno de los puntos más controversiales en las cláusulas referidas a la expropiación es lo que se denomina expropiación indirecta. Es decir, que subas impositivas o medidas que apunten a una mayor injerencia del estado, pueden ser interpretadas como formas indirectas de expropiación. Por ejemplo, la revocación de una concesión petrolera o la prohibición de fabricar determinados combustibles, bajo el amparo de criterios medio ambientales de interés público, pueden significar una desvalorización de las inversiones; aunque éstas no hayan sido expropiadas de manera directa. En la actualidad, existen por lo menos 49 disputas relacionadas con este problema sometidas a arbitraje internacional en el marco del TCE (ENERGY CHARTER SECRETARIAT, 2012). La defensa del inversor extranjero ante una eventual "expropiación indirecta" está contemplada en todos los TBI firmados por los países de la OPEP.

de un contrato, con inclusión de la amortización del principal y el pago de intereses devengados en virtud de un acuerdo de préstamo; d) de los ingresos no gastados y otras remuneraciones del personal contratado en el extranjero en relación con dicha inversión; e) del producto obtenido de la venta o liquidación de la totalidad o parte de una inversión; f) de los pagos derivados de la solución de una controversia; g) de los pagos de indemnizaciones con arreglo a los artículos 12 y 13." (TRATADO SOBRE LA CARTA DE ENERGÍA, 1994, art. 14, punto 1).

13 "Las transferencias efectuadas en virtud del apartado 1) se realizarán sin demoras y (excepto en el caso de un rendimiento en especie) en una divisa libremente convertible." (TRATADO SOBRE LA CARTA DE ENERGÍA, 1994, art. 14, punto 2).

14 "El importe de la indemnización equivaldrá al justo valor de mercado de la inversión expropiada inmediatamente antes de que el anuncio de la expropiación o de la intención de llevar a cabo la expropiación hubiese afectado al valor de la inversión (en lo sucesivo denominado "fecha de valoración")." (TRATADO SOBRE LA CARTA DE ENERGÍA, 1994, art. 13, punto 1). 
Si bien, tanto el TCE como la generalidad de los TBI diluyen la relación entre terratenientes y arrendatarios en una relación entre inversionistas, no puede abstraerse de la propiedad de los recursos y su base nacional. En este sentido está dedicado el artículo 18: "Soberanía sobre los recursos energéticos". En pocas palabras, dicho artículo reconoce que cada país es soberano en términos de decidir que mina o yacimientos se explota. Este artículo no puede si no llamarnos la atención. Mientras el conjunto del TCE apunta a reducir el poder de la propiedad nacional al mínimo, el artículo 18 pareciera ir en sentido contrario. Según autores como Mommer (2003, p. 209), la redacción de este artículo fue central para poder avanzar en el acuerdo entre países consumidores y poseedores de recursos naturales como Noruega. Allí se observa que el TCE no promueve la privatización de los yacimientos. Tampoco promueve la privatización de empresas estatales. Sin embargo, como se explicó anteriormente, la propiedad nacional no es simplemente propiedad estatal. Lo que aquí estamos evaluando no es si los nuevos tratados de inversión ponen límites a la propiedad estatal, sino a la propiedad de tipo nacional.

Podemos afirmar que la normativa contemplada en la TCE, o en los TBI, no expresa el intento de privatización de las compañías estatales. La privatización de compañías estatales no pareciera ser un punto en la agenda de los tratados bilaterales y multilaterales de inversión, sino la transformación de las mismas de ser captadores de renta para ser distribuida dentro del espacio nacional bajo distintas formas, a compañías que operen bajo los mismos parámetros de la compañía privada internacional. Donde el principio de trato nacional y de nación más favorecida se extiende al trato brindado por las compañías estatales a terceros. Es decir, lo que se está estableciendo es que las compañías estatales, no puedan brindar privilegios discriminando al inversor extranjero y acortando la capacidad de gravar las actividades del sector. Guardando las formas diplomáticas propia de esta clase de tratados, se establece que las empresas estatales no pueden, por ejemplo, priorizar a tal o cual proveedor-comprador por criterios de nacionalidad u otro tipo. Es decir, las empresas energéticas seguirán siendo estatales, pero deben actuar como se espera que actúe una empresa privada. Como era de esperar, dentro de los países de la OECD, Noruega fue uno de los países que más se opuso a existencia de cláusulas antidiscriminatorias en las fases de pre-inversión y de inversión (HUNTER, 2011, p. 12). La distinción entre pre-inversión e inversión e muy importante, aunque en el tratado no está claramente especificada. Si bien, en el artículo 10 del TCE se afirma que los estados de los países miembros:

De conformidad con las disposiciones del presente Tratado, las Partes Contratantes fomentarán y crearán condiciones estables, equitativas, favorables y transparentes para que los inversores de otras Partes Contratantes realicen inversiones en su territorio. Entre dichas condiciones se contará el compromiso de conceder en todo momento a las inversiones de los inversores de otras Partes Contratantes un trato justo y equitativo. 
Estas inversiones gozarán asimismo de una protección y seguridad completas y ninguna Parte Contratante perjudicará en modo alguno, mediante medidas exorbitantes o discriminatorias, la gestión, mantenimiento, uso, disfrute o liquidación de las mismas (TRATADO SOBRE LA CARTA DE ENERGÍA, 1994, art. 10).

Sin embargo, no se establece ninguna reglamentación específica para la fase previa al contrato de inversión. La no explicitación de una reglamentación que comprenda ambas fases no es accidental, sino que es parte de negociaciones que todavía no han llegado a resolución. De esta manera, los estados nacionales pueden pactar en la fase previa a la inversión condiciones para la obtención de licencias que apunten a, por ejemplo, beneficiar a capitales locales. Medidas que luego están estrictamente vedadas en la fase de inversión propiamente dicha. En la práctica, el TCE posee sustancia real en la fase de inversión (HUNTER, 2011, p. 9)

Por último, respecto de los impuestos, el TCE se limita a establecer que el trato nacional se sigue aplicando y que reserva al capital extranjero la posibilidad de presentar una suba impositiva como una forma de expropiación indirecta, bajo las condiciones antes descriptas.

En definitiva, el TCE supone una transformación significativa en los sistemas de propiedad acotando al ejercicio de la propiedad de tipo nacional a una mínima expresión. Para ello, no requiere de la privatización de empresas públicas o de los yacimientos. De ningún modo se cuestiona la propiedad estatal de los mismos. Por el contrario, su objetivo es la libre propiedad estatal. Es decir, la propiedad estatal liberada al capital petrolero transnacional. En esta transformación, las empresas estatales tienen un rol que jugar: pasar de ser vectores de la propiedad nacional a vectores de una propiedad sobre nuevas bases que buscan liberar al capital petrolero de trabas que impone la propiedad nacional.

Respecto de los países de la OPEP, como dijimos, su incorporación todavía se encuentra en proceso de largas negociaciones, aunque países como Venezuela estuvieron a poco de incorporarse durante la década de $1990 .{ }^{15}$ De todas formas, como hemos venido señalando, durante las últimas décadas, dichos países han firmado numerosos TBI que comprenden muchas cláusulas idénticas al TCE y que, en nuestra opinión, marcan un antecedente en un nuevo e incipiente régimen territorial. Para dar cuenta de ello, hemos analizado la totalidad de los TBI firmados por los principales países de la OPEP con países de la OECD. En total, analizamos cuarenta y tres TBI (ver Tabla 1).

15 El acercamiento de Venezuela a la agenda del TCE se dio en el marco del proceso conocido como "Apertura Petrolera", durante el cual se redujo la participación fiscal del Estado en los ingresos petroleros y se buscó a potenciar la producción local en contradicción con el sistema de cuotas de la OPEP (DACHEVSKY, 2014). 
Tabla 1 - Tratados Bilaterales de Inversión firmados entre países seleccionados de la OPEP y países centrales

\begin{tabular}{c|c|c|c|c|c|c|c}
\hline País & Venezuela & $\begin{array}{c}\text { Arabia } \\
\text { Saudita }\end{array}$ & Irán & Libia & Nigeria & Kuwait & Qatar \\
\hline Alemania & 1996 & 1996 & 1965 & & 2000 & & 1996 \\
\hline Austria & & 2003 & 2001 & 2002 & & 1998 & \\
\hline Bélgica & 1998 & 2001 & & 2004 & & & \\
\hline Canadá & 1996 & & & & & & \\
\hline China & & & 2000 & & & 1985 & 1999 \\
\hline Dinamarca & 1997 & & & & & $*$ & \\
\hline España & & & $*$ & & 2002 & & \\
\hline Finlandia & & & & & 2005 & 1996 & \\
\hline Francia & 2001 & $*$ & 2003 & & 1991 & 1989 & $*$ \\
\hline Holanda & & & & & $*$ & 2001 & \\
\hline Inglaterra & & & & & & & \\
\hline Italia & 1990 & $*$ & & 2003 & & 1987 & \\
\hline $\begin{array}{c}\text { Reino } \\
\text { Unido }\end{array}$ & 1995 & & & & 1990 & & \\
\hline Suecia & 1998 & & & & & & \\
\hline Suiza & 1993 & 2006 & 1998 & 2003 & 2004 & & 2001 \\
\hline
\end{tabular}

Fuente: United Nations Conference on Trade and Development (2013).

Nota: (*) No disponemos del año de firma del TBI.

En síntesis, la amplia mayoría de los tratados no presenta variaciones significativas entre sí. Es decir, todos los tratados postulan principios similares en lo referido a la definición de inversión, donde se toma una definición idéntica a la empleada por el TCE, a la exigencia de trato nacional, a total e irrestricta libertad para transferir divisas al exterior al tipo de cambio de mercado y a los derechos frente a formas de expropiación directas o indirectas. Es decir, en todos los tratados firmados por los países de la OPEP están contenidos los puntos centrales del TCE. Es decir, podemos afirmar que la no inclusión formal de la OPEP en el TCE, no significa que, en la práctica, sus países miembros no hayan comenzado a sujetarse a sus principios.

La principal diferencia que encontramos entre los TBI firmados por los países de la OPEP y el TCE, además del carácter bilateral del primero y el carácter multilateral del segundo, reside en que los TBI no explicitan ninguna clase de prohibición respecto de políticas que condicionen al inversor extranjero con cuotas de compre nacional o exigencias de niveles de performance de exportación, para 
poder importar. La única excepción en este sentido es Venezuela con el TBI firmado con Canadá en 1996. En dicho tratado, se establece explícitamente que ninguna parte contratante puede fijar restricciones de origen (compre nacional), restricciones a las exportaciones, restricciones a la transferencia de tecnología (TBI Venezuela-Canadá, 1996, Anexo: punto II.6). Cabe aclarar, el tratado exceptúa de las restricciones al compre nacional al empleo de mano de obra. Venezuela se reserva el derecho de que el $90 \%$ de la mano de obra destinada a trabajos manuales y no manuales sean de origen venezolano, siempre y cuando esto no signifique, para el inversor, una perdida en la capacidad de decisión (TBI Venezuela-Canadá, 1996, Anexo: punto II.11.d.ii). Quizás la excepción más importante que diferencia al TBI entre Venezuela y Canadá respecto del TCE es que Venezuela resguarda a sus empresas estatales de tener que cumplir con las disposiciones del tratado. Es decir, el inversor canadiense no puede demandar recibir el mismo trato que la empresa estatal, así como tampoco se puede exigir a la empresa estatal cumplir con las normas del tratado. De esta manera, la empresa estatal conserva un lugar especial que no puede ser tomado como referencia para inversores privados. Fuera de estas excepciones, en todos los casos observamos que los puntos referidos al trato de inversiones extranjeras en el territorio que definen la posibilidad de evitar la salida de renta del espacio nacional están fuertemente limitados medidas que permiten interpretar subas impositivas como formas de expropiación indirecta y por la total libertad para la transferencia de divisas al exterior.

Debemos preguntarnos entonces qué impulsa a los países exportadores a firmar y respetar esta clase de tratados. Como ya dijimos, hay que tener en cuenta que la protección del inversor extranjero dejó de ser sólo un interés de las compañías privadas, sino también de las propias compañías nacionales que día a día suman activos potencialmente embargables en el exterior.

\section{Condicionamientos Actuales para la Planificación del Desarrollo}

A pesar de haber perdido peso como objeto de estudio por la bibliografía económica, la renta de la tierra no perdió importancia en tanto sostén de una importante cantidad de países cuyos ciclos siguen estando dominados por las variaciones de los precios de las materias primas. Basta con analizar la participación todavía dominante de las exportaciones de materias primas en los países de América Latina, África y buena parte de Asia para dar cuenta de la centralidad que todavía tiene la renta.

Aquí señalamos la aparición de lo que denominamos como propiedad nacional del petróleo se desarrolló con el objeto de garantizar la apropiación de una mayor cantidad de renta posible en el marco internacional para el sostenimiento 
de actividades no petroleras en su interior emergió en países de la OPEP, desembocando en las nacionalizaciones petroleras.

Sin embargo, el desarrollo pleno de las compañías nacionales, en el marco de la nueva estructura internacional de la industria petrolera generada luego de la crisis de 1973, las impulsa a dejar comportarse de acuerdo a sus propósitos originales. El avance no definitivo y en forma embrionaria de acuerdos bilaterales y multilaterales de protección del inversor extranjero parecieran marcar una agenda a futuro en la cual, si bien la reprivatización de dichas compañías no aparece explicitada, si su transformación en empresas que cada vez se diferencien menos de las privadas. A ello deberá sumársele la extensión de nuevos acuerdos de producción entre compañías nacionales e internacionales por los cuáles, se le exime al capital privado de todo tipo de pago de impuestos, regalías, etc. hasta tanto no haya recuperado su inversión. Estos "Acuerdos de Producción Compartida" que ya vemos ya aplicarse en distintos países parecen contener los principios que regularán al resto de las compañías nacionales a futuro (AMEH, 2007, p. 11).

Las razones de este cambio no pueden explicar se mirando sólo a la industria petrolera, sino que dando cuenta del fracaso de los sectores no petroleros de los países exportadores. El retroceso de la propiedad nacional no expresa sino el retroceso de aquellos sectores que se han beneficiado con ella. Sectores cuya supervivencia se encuentra tan atada a las oscilaciones de los ingresos rentísticos como hace cuatro décadas, en un contexto internacional mucho más competitivo.

\section{Referências}

AL-CHABALI, F. J. La OPEP y el precio internacional del petróleo: el cambio estructural. México: Siglo XXI, 1984.

AL-MONEEF, M. Vertical integration strategies of the national oil companies. The Developing Economies, v. 36, n. 4, p. 203-222, June 1998.

$\mathrm{AMEH}, \mathrm{M}$. The shift from joint operating agreements to production sharing contracts in the Nigerian oil industry: any benefits for the players? CEPMLP Annual Review, UK, v. 10, 2007.

AZERBAIJAN-USA. Treaty between the Government of the United States of America and the Government of the Republic of Azerbaijan concerning the encouragement and reciprocal protection of investment. Baku, 8 de agosto de 2000. Disponible en: <http:// investmentpolicyhub.unctad.org/Download/TreatyFile/246>. Acceso en: 30082012.

BAPTISTA, A. Bases cuantitativas de la Economía Venezolana, 1830-2002. Caracas: Fundación Empresas Polar, 2006.

BINA, C. Oil: a time machine. Journey beyond fanciful economics and frightful politics. New York: Linus Publications, 2011. 
BRITISH PETROLEUM. Statistical review of world energy. 2014. Disponible en: < http:/www. bp.com/content/dam/bp-country/de_de/PDFs/brochures/BP-statistical-review-of-worldenergy-2014-full-report.pdf > . Acceso en: 06 mayo 2014.

BUREAU OF LABOR STATISTICS. Labor Productivity and Costs by Industry Tables. Disponible en http://www.bls.gov/lpc/lpc_by_industry_and_measure.xlsx. Acceso en: 05 ago. 2014.

Producer price index industry data. Disponible en: < http://data.bls.gov/pdq/ SurveyOutputServlet>. Acceso en: 05 ago. 2014.

CENTRAL BANK OF IRAN. Annual national accounts. Central Bank of the Islamic Republic of Iran, economic accounts department. Disponible en: < http://www.cbi.ir/simplelist/5796. aspx> Acceso: 06 ago. 2014

CHEVALIER, J. M. La baza del petróleo. Barcelona: Laia Paperback, 1974.

DACHEVSKY, F. Del Socialismo del Siglo XXI a la crisis de la propiedad nacional. Análisis del proceso venezolano (1999-2014), In: JORNADAS DE ECONOMÍA CRÍTICA, 4., 2014, La Plata. Anais... La Plata: Escuela de Economía Política, 2014.

. La disputa internacional por la renta petrolera y la fijación de los precios del petróleo. Razón y Revolución, Buenos Aires, n. 22, p. 163-184, 2011 a.

. La renta de la tierra y sus efectos en la acumulación de capital. El caso venezolano (1980-2010). 130 f. Tesis (Maestría en Relaciones Económicas Internacionales) - Facultad de Ciencias Económicas, Universidad de Buenos Aires, Buenos Aires, 2011 b.

. Tierra y capital en la industria petrolera argentina. El desarrollo de la propiedad nacional de los hidrocarburos (1907-1975). 17 f. Tesis (Doctorado en Historia) - Facultad de Filosofía y Letras, Universidad de Buenos Aires, Buenos Aires, 2013.

ENERGY CHARTER SECRETARIAT. Expropriation regime under the energy charter treaty. Bruselas: Energy Charter Secretariat, 2012.

ENERGY INFORMATION ADMINISTRATION. Base de datos. Disponible en: < https://www. eia.gov/dnav/pet/pet_crd_crpdn_adc_mbbl_m.htm >. Acceso en: 02 jul. 2014.

GRIFFIN, J.; TEECE, D. OPEC behaviour and world oil prices. London: George Allen and Unwin, 1982.

HIRSCH, R. Mitigation of maximum world oil production: shortage scenarios. Energy Policy, v. 36, n. 2, p. 881-889, 2008.

HOWARTH, S.; JONKER, J. A history of Royal Dutch Shell, powering the hydrocarbon revolution, 1939-1973. Oxford, UK: Oxford University Press, 2007. v. 2.

HUNTER, T. The energy charter treaty as a means of developing national industry and commerce in the exploitation of petroleum resources: an analysis of the application of articles 5, 10 and 22 of the energy charter treaty. Oil, gas 8 Energy Intelligence Law, Voorburg, Netherlands, v. 9, p. 1-28, Mar. 2011. 
IÑIGO CARRERA, J. El capital: razón histórica, sujeto revolucionario y conciencia. Buenos Aires: Imagomundi, 2008.

MARCEL, V. Oil titans. National oil companies in the Middle East. Washington, D.C.: Brooking Institution Press, 2006.

MARX, K. El capital: el proceso global de producción capitalista. México: Siglo XXI, 1981. v. 8. Tomo III.

. Elementos fundamentales para la crítica de la economía política (Grundisse) 18571858. Madrid: Siglo XXI, 2009. Tomo 1.

MAUGERI, L. The age of oil: the mythology, history and future of the world's most controversial resource. Guilford: Praeger, 2006.

MILLER, E. Some implications of land ownership patterns for petroleum policy. Land Economics, v. 49, n. 4, 414-423, 1973.

MOMMER, B. La cuestión petrolera. Caracas: UCV, 1988.

. Petróleo global y estado nacional. Caracas: Comala 2003.

MURRAY, B.; KISHAN, S. OPEC producers increase refinery investments to avert shortages. 2005. Disponible en: <http://www.bloomberg.com/apps/news?pid=newsarchiveEssid=aLfu tyiuqIJQËrefer $=$ news_index $>$. Acceso en: 10 ago. 2013.

ORGANIZATION OF THE PETROLEUM EXPORTING COUNTRIES. Annual Statistical Bulletin. Disponible en: <http://www.opec.org/opec_web/en/publications/202.htm>. Acceso: 05 jun. 2014.

PARRA, F. Oil politics: a modern history of petroleum. London: IB Tauris, 2004.

RIVERO, R. El imperialismo petrolero y la revolución venezolana. Caracas: Fondo Editorial Salvador de la Plaza, 1979.

TRATADO SOBRE LA CARTA DE ENERGÍA. 1994. Disponible en: < http://www. energycharter.org/fileadmin/DocumentsMedia/Legal/ECT-es.pdf>. Acceso en: 15112013.

UNITED NATIONS CONFERENCE ON TRADE AND DEVELOPMENT. Investment Policy Hub. Disponible en: < http://investmentpolicyhub.unctad.org/IIA> . Acceso: 28 nov. 2013.

UNITED NATIONS INDUSTRIAL DEVELOPMENT ORGANIZATION. Industrial Statistics Database. INDSTAT 4. Disponible en: < http://stat.unido.org> . Acceso en: 05 ago. 2014.

WOLF, C. Does ownership matter? Cross-sectional evidence on state oil vs. private oil. 1987-2006. 2008. Disponible en: <https://www.repository.cam.ac.uk/bitstream/ id/534309/0828EEPRG0813.pdf> . Acceso en: 30 nov. 2013.

WORLD BANK. World Development Indicators. Disponible en: < http://data.worldbank.org/ topic/economy-and-growth>. Acceso en: 05 ago. 
ZANDEN, J. L. A history of Royal Dutch Shell, appendices. Oxford, UK: Oxford University Press, 2007.

Recebido em: 08/09/2014. Aceito em: 27/07/2015. 